\title{
Mitosis and cell death in the optic lobes of workers, queens and drones of the honey bee (Apis mellifera) during metamorphosis
}

\author{
Thaisa Cristina Roat* and Carminda da CRuz Landim \\ Departmento de Biologia, Instituto de Biociências - Universidade Estadual Paulista \\ “Júlio de Mesquita Filho" (UNESP), Av. 24A, no. 1515, Bela Vista, 13506-900 Rio Claro, SP, Brazil \\ "Corresponding author (Fax, +55 19 3526-4136; Email, thaisaroat@yahoo.com.br)
}

Colonies of the honey bee, Apis mellifera, consist of males and two female castes: workers and queens. The castes and males from A. mellifera have a distinct morphology, physiology and behaviour that correlate with their roles in the society and are characterized by some brain polymorphisms. Compound eyes are one of the characteristics that differ among the castes and sexes. A. mellifera is a holometabolous insect; therefore, the development of adult organs during metamorphosis, which will produce these differences, requires the precise coordination of three main programmed cellular processes: proliferation, differentiation and death. These processes take place simultaneously during pupation. Our purpose was to investigate cell division and death in the optic lobes (OL) of workers, queens and males during pupation to identify how the differences in the compound eyes in adults of these classes are achieved. The results showed that OL differentiation follows a similar pattern in the three classes of individuals studied, without structural differences in their development. The main non-structural differences involve cell division, mortality rates and timing. The results suggest a modelling of the brain during differentiation, which contributes to the specific functions of each individual class.

[Roat T C and Landim C C 2010 Mitosis and cell death in the optic lobes of workers, queens and drones of the honey bee (Apis mellifera) during metamorphosis; J. Biosci. 35 415-425] DOI 10.1007/s12038-010-0047-x

\section{Introduction}

The insect brain is the main nervous centre for associative integration of behavioural patterns, commanding the changes that result from learning (Snodgrass 1935, 1956; Chapman 1998). The insect brain consists of a protocerebrum, a deuterocerebrum and a tritocerebrum. The optic lobes (OL), which are part of the protocerebrum, consist of three layers of nerve fibres, intercalated by layers of neuron bodies or somata. This structure is responsible for the transduction of light stimuli and conduction to the mushroom bodies, where they trigger responses. Luminous stimuli are received by the optic lens and photoreceptor nerve cells, known as the retinulae, which are arranged in optical units called ommatidia (Snodgrass 1956; Cruz-Landim et al. 1979; Chapman 1998).
Like all holometabolous insects, Apis mellifera has a larval stage, in which the morphological and physiological characteristics differ from those of the adult. This larval stage is followed by a pupal stage, during which metamorphosis or pupal development is marked by changes on the surface of the pupa's body, specifically by an advance in compound eye pigmentation and cuticle darkening. Therefore, pupation can be divided into five stages marked by the parameters of white, pink, brown and black eyes, and the beginning of tegument darkening. Although the delimitation, duration and naming of these stages might change from author to author (Ganeshina et al. 2000), the advance in eye pigmentation and cuticle darkening remain reliable parameters for comparisons in physiological states.

The insect's metamorphosis offers a unique opportunity to investigate the basic mechanisms by which the larval

Keywords. Apoptosis; bee; brain; cell division; nervous system

Abbreviations used: BEP, brown pupae; BlEP, black-eyed pupae; BRdU, 5-bromo-2-deoxyuridine; BSA, bovine serum albumin; OL, optic lobe; PBS, phosphate buffered saline; PEP, pink pupae; PPB, pupae with darkening bodies; TUNEL, terminal deoxynucleotidyl transferasemediated deoxyuridine triphosphate nick-end labelling; WEP, white pupae 
nervous system undergoes morphological changes. When bee larvae develop into adults, their neuronal circuits (which in the larvae almost solely dictate activities such as feeding) are transformed to control processes, such as their reproductive behaviour, flight and, in the case of worker bees, various activities associated with hive provisioning and maintenance.

The development of adult organs requires the precise coordination of three main programmed cellular processes, which usually take place simultaneously: proliferation, differentiation and death. Studies with neuroblasts of holometabolous insects show that these cells divide continuously during the entire larval and pupal period, but all division is interrupted just before the adult emerges after pupation (Norlander and Edwards 1970; Truman and Bate 1988; Ito and Hotta 1992; Farris et al. 1999; Ganeshina et al. 2000). Because of this, all neurons differentiate during metamorphosis.

Death and neuroblast division can be morphologically examined using microscopy. Fahrbach et al. (1995), Farris et al. (1999) and Ganeshina et al. (2000) observed cell death in the mushroom bodies of A. mellifera in the mid-pupal stage. Nuclear morphology and physiology are areas of study involved in the characterization of cell death. Endonucleases cleave the DNA chain in the internucleosomal regions, giving rise to short fragments of approximately $180 \mathrm{bp}$. The fragmentation of DNA can be detected through immunocytochemical methods such as the terminal deoxynucleotidyl transferase-mediated deoxyuridine triphosphate nick-end labelling (TUNEL) reaction, which labels the $3^{\prime}-\mathrm{OH}$ ends of the nucleotides generated by the fragmentation.

In addition, immunolabelling with antibodies against phosphorylated histone $\mathrm{H} 3$ can be a useful tool to detect neuroblast division, because the phosphorylation of this histone is temporally correlated with mitotic chromosome condensation (Hendzel et al. 1997). In mammalian cells, phosphorylated histone $\mathrm{H} 3$ at serine 10 is detected by immunoreactions during prophase and remains until metaphase. From anaphase on, phosphorylation decreases, resulting in decreased immunoreactions; by telophase, phosphorylation ends so immunoreactions do not occur (Gurley et al. 1978; Paulson and Taylor 1982).
In eusocial bees such as A. mellifera, there is nutritional determination of the castes. Workers are responsible for all tasks related to colony maintenance (Winston 1987) while queens, after being fertilized by males, lay eggs and also play a role in controlling the physiology and behaviour of the workers (Butler 1957; Verheijen-Voogd 1959). It is assumed that the neural reorganization occurring during metamorphosis is related to the different roles played by each sex and caste in hive survival. This brain remodelling involves the death of some neurons and the production of new ones in each caste and sex. Nevertheless, most of the studies in this field focus on brain remodelling in workers, and comparative studies relative to the determination of brain differences among colony members is lacking. The purpose of this study was to investigate the cell division and death that occur in the OL during pupation to identify how the differences in the compound eyes of adult workers, queens and drones are established during metamorphosis.

\section{Materials and methods}

\subsection{Materials}

Fifth-instar larvae, pupae, newly emerged workers, queens and drones of Apis mellifera were collected from the apiary of the Department of Biology of the Institute of Biosciences of UNESP (Universidade Estadual Paulista "Júlio de Mesquita Filho") at Rio Claro.

\subsection{Methods}

2.2.1 Collection of specimens: (i) Workers: To obtain larvae, pupae and adult workers, an empty comb was placed in a hive to allow a queen to lay eggs. After $24 \mathrm{~h}$, the comb and eggs were transferred to an area for brood care and monitoring. When workers reached the fifth-instar stage, immediately before cell capping, the comb was removed from the hive, and the first collection was made. Collections were also made when workers reached the following stages: prepupae; white (WEPw), pink (PEPw), brown (BEPw) and

Table 1. Developmental stages of the honey bee used in this study

\begin{tabular}{|c|c|c|}
\hline Stage (in this work) & Ganeshina's stages & Features \\
\hline White-eyed pupae - WEP & $\mathrm{P} 0 / 1$ & White eyes and white body \\
\hline Pink-eyed pupae - PEP & $\mathrm{P} 2$ & Pink eyes and white body \\
\hline Brown-eyed pupae - BEP & P3 & Brown eyes and white body \\
\hline Black-eyed pupae - BlEP & P5 'early' & $\begin{array}{l}\text { Black eyes, darkened tibiotarsal joints of two pairs and slightly } \\
\text { darkened joints of the third pair }\end{array}$ \\
\hline Pupae with darkening bodies PPB & P9 & Dark brown body and legs, straight wings \\
\hline Newly emerged & Newly emerged & As soon as the bee emerges \\
\hline
\end{tabular}


black-eyed pupae (BlEPw); pupae with darkening bodies $(\mathrm{PPBw})$ and adults soon after emergence. Ganeshina et al. (2000) divided metamorphosis into 9 stages. In the present study, 5 of the 9 stages of metamorphosis, as defined by Ganeshina et al. (2000), were examined, and are listed in table 1. (ii) Queens: Larvae less than $32 \mathrm{~h}$ old were transferred from their original cells to artificial queen wax caps with a drop of royal jelly, according to the method described by Doolittle (1899). These caps were returned to the hive, where the larvae continued to be fed by workers with queen food and monitored for the collection of fifthinstar larvae and those in the following stages: prepupal; white (WEPq), pink (PEPq), brown (BEPq), and black-eyed pupae (BlEPq); pupae with darkening bodies (PPBq) and newly emerged queens. (iii) Drones: Fifth-stage larvae; prepupae; white (WEPd), pink (PEPd), brown (BEPd), black-eyed pupae (BlEPd); pupae with darkening bodies ( $\mathrm{PPBd}$ ) and newly emerged males were collected from drone cells directly in the hive.

2.2.2 Brain morphology: The brains of at least five individuals from each group were prepared for light microscopy examination. These brains were dissected in buffered saline solution for insects $(\mathrm{NaCl} 7.5 \mathrm{~g} / \mathrm{l}$, $\mathrm{Na}_{2} \mathrm{HPO}_{4} 2.38 \mathrm{~g} / \mathrm{l}$ and $\mathrm{KH}_{2} \mathrm{PO}_{4} 2.72 \mathrm{~g} / \mathrm{l}$ ) and fixed in $4 \%$ paraformaldehyde in a $0.1 \mathrm{M}$ sodium phosphate buffer (pH 7.4). The brains were washed with the same buffer and dehydrated in 30-min baths in ascending concentrations of ethanol $(70 \%, 80 \%, 90 \%$ and $95 \%)$, and embedded in Leica historesin for three days. Blocks were later sectioned to a thickness of $5 \mu \mathrm{m}$. The sections were mounted on slides, stained with haematoxylin and eosin, and mounted in Canada balsam following standard procedures.

2.2.3 TUNEL reaction for cell death: The heads or brains of specimens at the same stage, and of the same sex and castes as described above were dissected in buffered saline solution for insects and fixed in $4 \%$ paraformaldehyde in a $0.1 \mathrm{M}$ sodium phosphate buffer, $\mathrm{pH}$ 7.4. After dehydration in an ethanol series and diaphanization in xylene, the brains were embedded in histosec (Merck, Germany).

Sections of $8 \mu \mathrm{m}$ thickness were transferred to albuminized histological slides and oven-dried at $37^{\circ} \mathrm{C}$. The histosec was removed with several xylene washes, and the section was then subjected to the TUNEL reaction (Roche Molecular Biochemicals - ISCDDK in situ Cell Death Detection Kit), following the manufacturer's instructions. Negative and positive controls were prepared.

The fluorescein-stained 3'-OH ends of histone were observed by fluorescence microscopy (Microscope BX 51, Olympus America Inc).

2.2.4 Morphometry of the cell death area: The areas of cell death in the OLs were measured in histological serial sections. Twenty measurements from workers, queens and drones were taken using Leica Qwin 550 Servers - Image
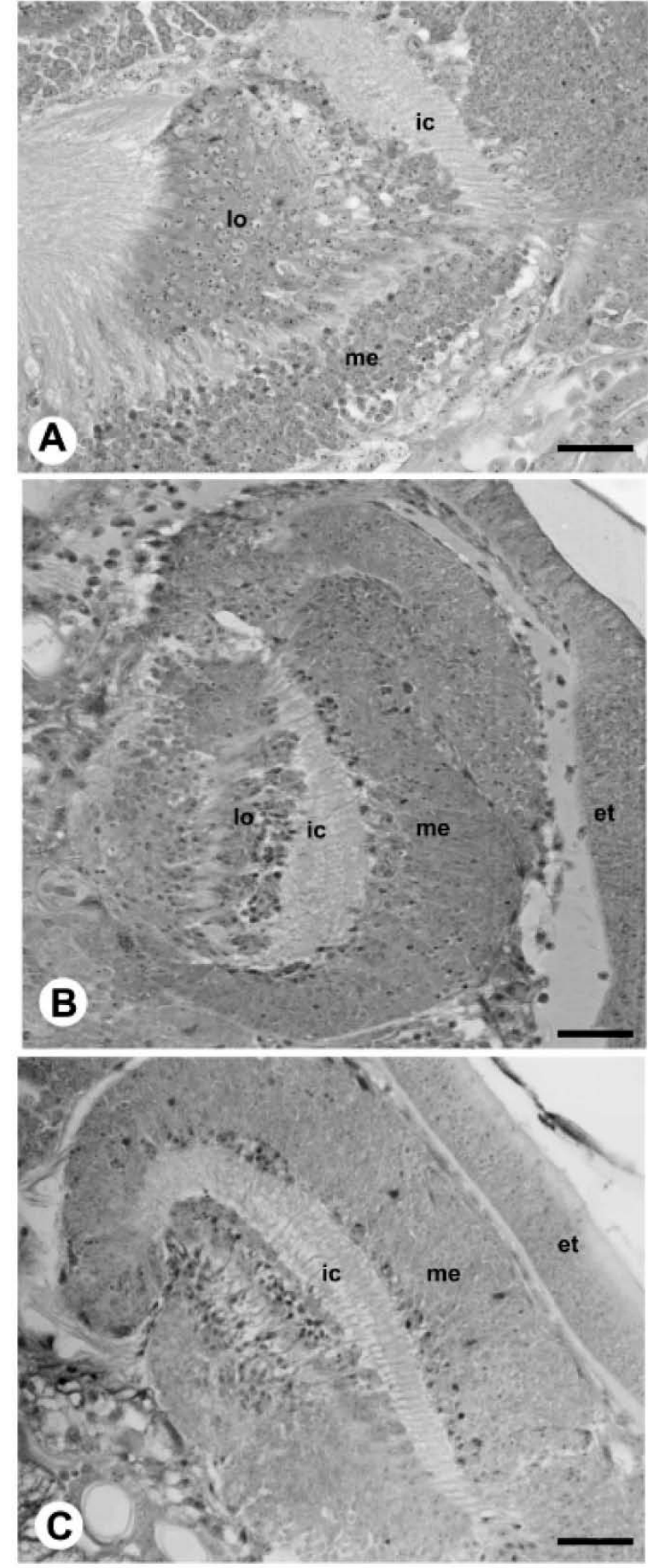

Figure 1. Light micrographs of histological sections from the optic lobes of fifth-instar larvae of $A$. mellifera. (A) Workers, (B) queens and $(\mathbf{C})$ drones. Note the primordial optic lobe consisting of somata layers called lobula (lo) and medulla (me), and the neuropil layer called the inner chiasmata (ic). It is possible to see the epidermal thickening (et) in B and C. Bars: A $400 \mu \mathrm{m}$; B and C $600 \mu \mathrm{m}$. 
Peripheral Serve Software. To obtain the histological measurements, sections showing the OLs in the medial frontal section were used. A non-parametric ANOVA variance analysis (Siegel and Castellan 1988) was performed to evaluate differences at a level of significance of $P \leq 0.05$. Significant differences between individual classes were identified using the Tukey multiple range test.

2.2.5 Detection of cell division: The brains of five individuals in each class were fixed for 3 days in $4 \%$ paraformaldehyde in phosphate buffered saline (PBS) (10 $\mathrm{mM}, \mathrm{pH}$ 7.5), washed in buffer and permeabilized in PBST
(0.1\% Triton-100 in PBS $10 \mathrm{mM}, \mathrm{pH} 7.5)$ for $1 \mathrm{~h}$ at room temperature. The brains were washed again in buffer and incubated for $1 \mathrm{~h}$ in $1 \%$ bovine serum albumin (BSA). Next, they were incubated for $1 \mathrm{~h}$ with $20 \mu \mathrm{l}$ of IgG polyclonal antibody rabbit anti-phosphorylated histone H3 (Sigma, USA) diluted 1:100 with 1\% BSA in PBS (10 mM, pH 7.5).

The brains were then washed in buffer once more and incubated overnight at $4^{\circ} \mathrm{C}$ in $20 \mu \mathrm{l}$ of fluoresceinconjugated anti-goat IgG secondary antibody (CY3 - Sigma USA), diluted $1: 100$ with $1 \%$ BSA in PBS $(10 \mathrm{mM}$, pH 7.5), and conjugated with fluorescein. This procedure was

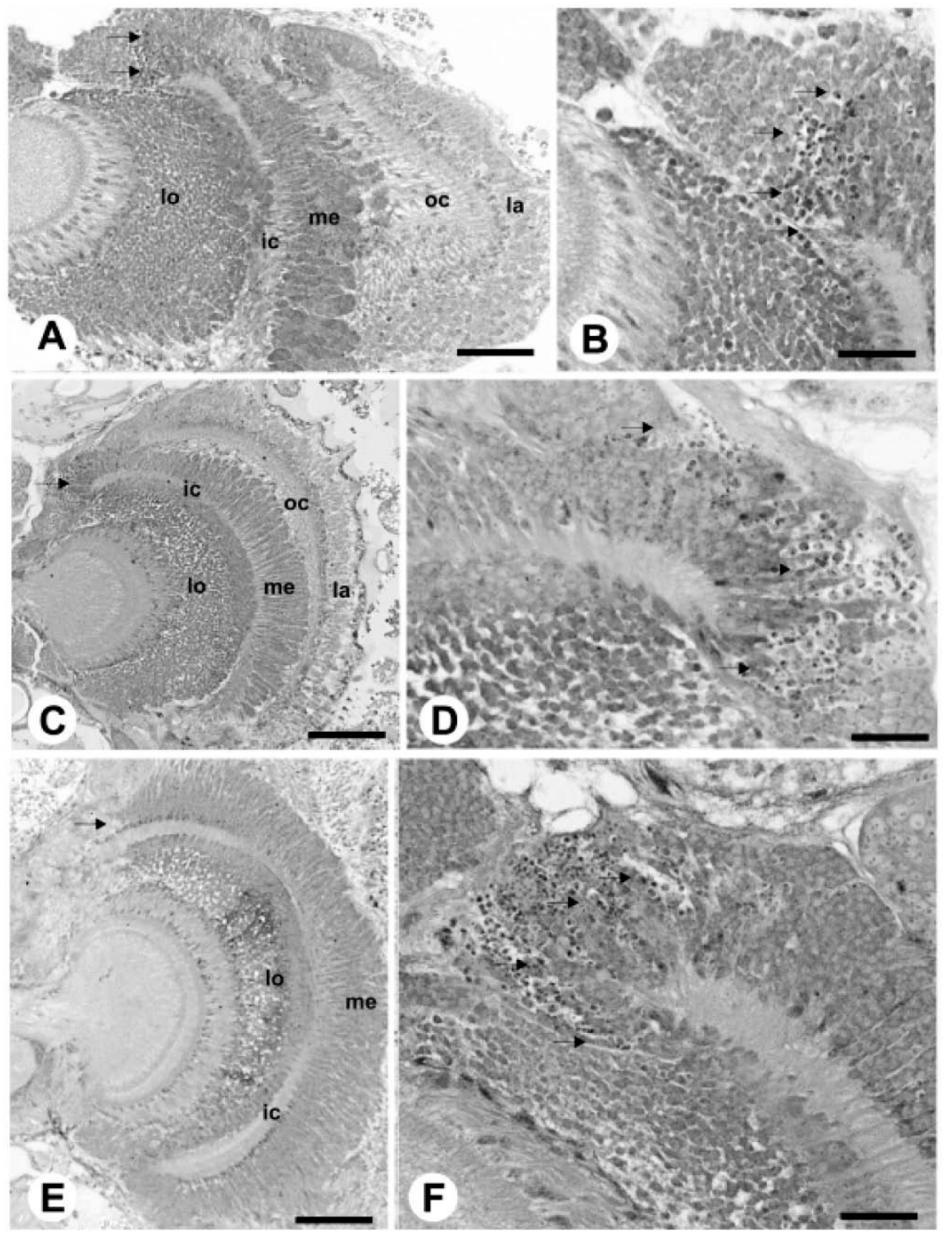

Figure 2. Light micrographs of histological sections from the optic lobes of white-eyed pupae of $A$. mellifera. (A) and (B) Workers; (C) and (D) queens; (E) and (F) drones. Note the cells with pyknotic nuclei (arrow) indicating cell death. In queens and drones, note that the optic lobes are more differentiated, and in workers the neuroblasts in the medullar layer are arranged in columns. lo, lobula; ic, inner chiasmata; me, medulla; oc, outer chiasmata; la, lamina. Bars: B, D and F $400 \mu \mathrm{m} ; \mathbf{A}: 600 \mu \mathrm{m}$; C and E: $800 \mu \mathrm{m}$. 
followed by another wash with buffer, after which the brains were mounted in a medium consisting of $90 \%$ glycerol, $0.1 \%$ sodium azide and 3\% n-propyl gallate in PBS (10 $\mathrm{mM}, \mathrm{pH}$ 7.5). The results were analysed by fluorescence microscopy (Microscope BX 51, Olympus America Inc) at 450-500 nm.

\section{Results}

\subsection{Differentiation of OL during metamorphosis}

During the larval stage, the brain develops the OL primordia. In fifth-instar larvae, the OL primordia consist mostly of

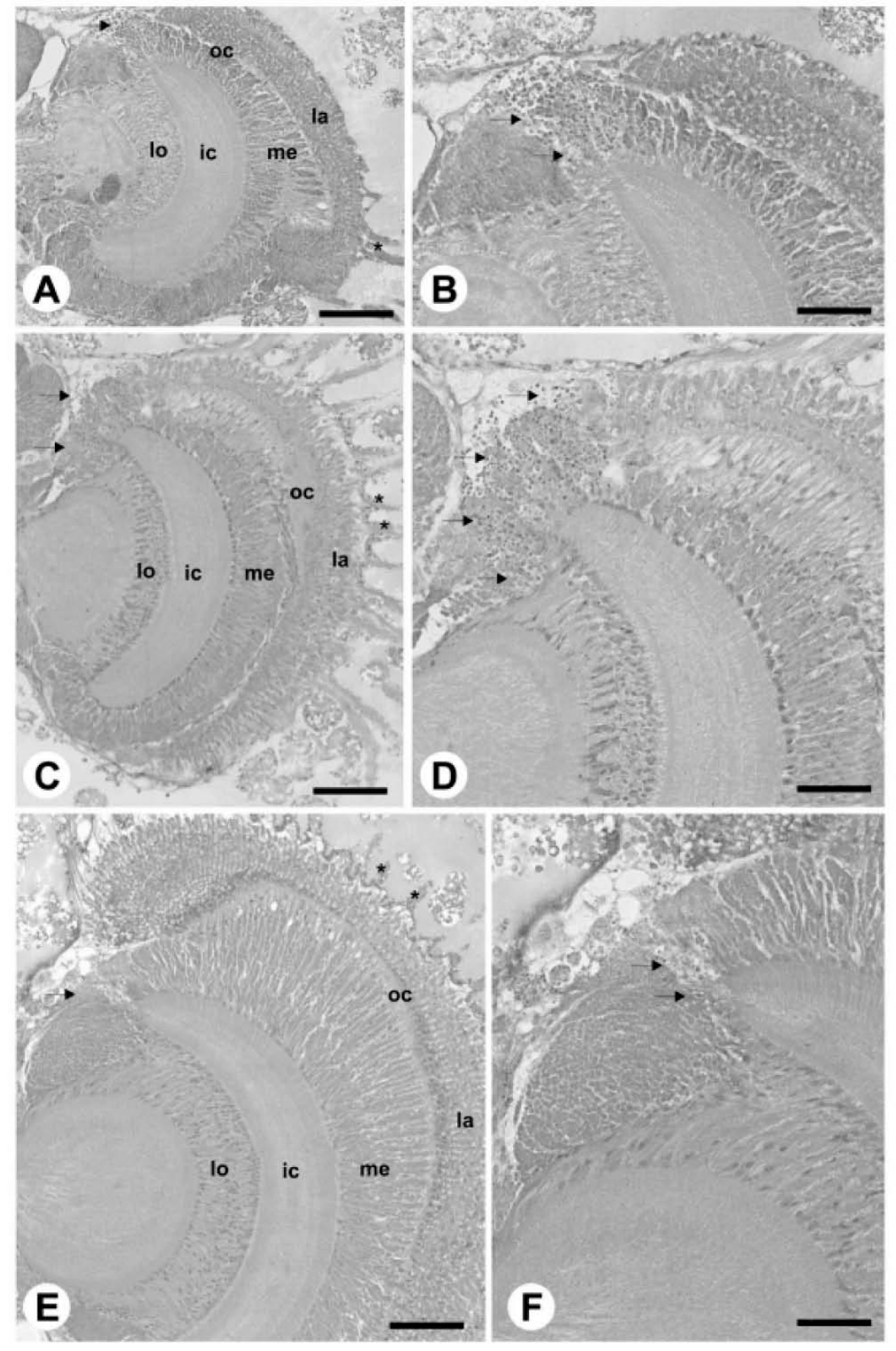

Figure 3. Light micrographs of histological sections from the optic lobes of pink-eyed pupae of $A$. mellifera. (A) and (B) Workers; (C) and (D) queens; (E) and (F) drones. Note cell death (arrow) at the edges, which is more frequent in queens (C - detail D) and workers $(\mathbf{A}$ - detail B) and less frequent in drones $(\mathbf{E}$ - detail $\mathbf{F})$. Note also the beginning of differentiation in the reticular layer (asterisk). lo, lobula; me, medulla; ic, inner chiasmata; oc, outer chiasmata; la, lamina. Bars: B, D and F $400 \mu \mathrm{m}$; A and C $600 \mu \mathrm{m} ; \mathbf{E ~} 800 \mu \mathrm{m}$. 


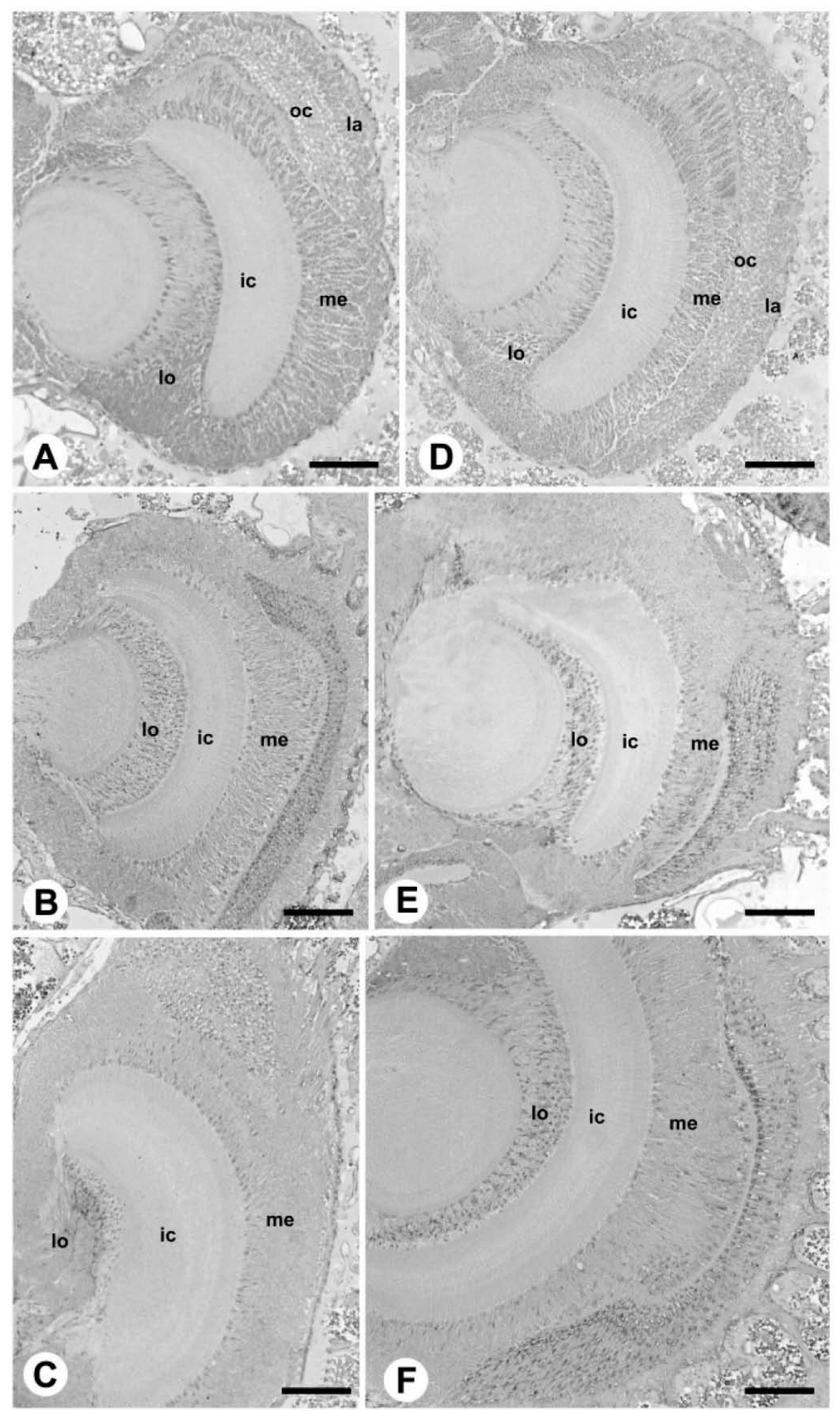

Figure 4. Light micrographs of histological sections from the optic lobes of brown-eyed pupae (A-C) and black-eyed pupae (D-F) of A. mellifera. Note the fully structured optic lobes. lo, lobula, ic, inner chiasmata; me, medulla; oc, outer chiasmata; la, lamina. Bars: A, B, C, D and E $800 \mu \mathrm{m} ; \mathbf{F} 600 \mu \mathrm{m}$. 
neuroblasts. The neuropil layers are reduced; therefore, only the inner chiasma, consisting of the neurites of the differentiating neuroblasts, are visible. In this stage, the OL in all the individual classes display the same morphology (figures $1 \mathrm{~A}-\mathrm{C}$ ).

In the WEP stage, more neuroblasts differentiate into neurons in all individual classes, causing an increase in neuropil extension and the appearance of well-defined outer and inner chiasmata. Cells with pyknotic nuclei are visible concomitantly with differentiation in the somata layers, indicating cell death (figure $2 \mathrm{~A}-\mathrm{F}$ ). In this stage, OL differentiation appears to be more advanced in drones (figure 2E-F) and queens (figure 2C-D). The neuroblasts in the medullar layer are arranged in columns. Cell death is always seen at the edges of the OL sections.

The OL of bees at the PEP stage show more well-defined cellular and neuropil layers compared to those in the WEP stage, and continue to show zones of nuclear pyknosis in workers (figure $3 \mathrm{~A}$ and $\mathrm{B}$ ), queens (figure 3C and D) and drones (figure $3 \mathrm{E}$ and $\mathrm{F}$ ), though at a lower frequency in drones than in workers and queens. The neuroblasts of the medullar layer are still arranged in columns perpendicular to the epidermis (figure 3B), but neurites begin to appear at the inner face of the layer. The outer lamina possesses projections directed toward the epidermis, which correspond to differentiation of the retinular layer (figure $3 \mathrm{~A}$ ).

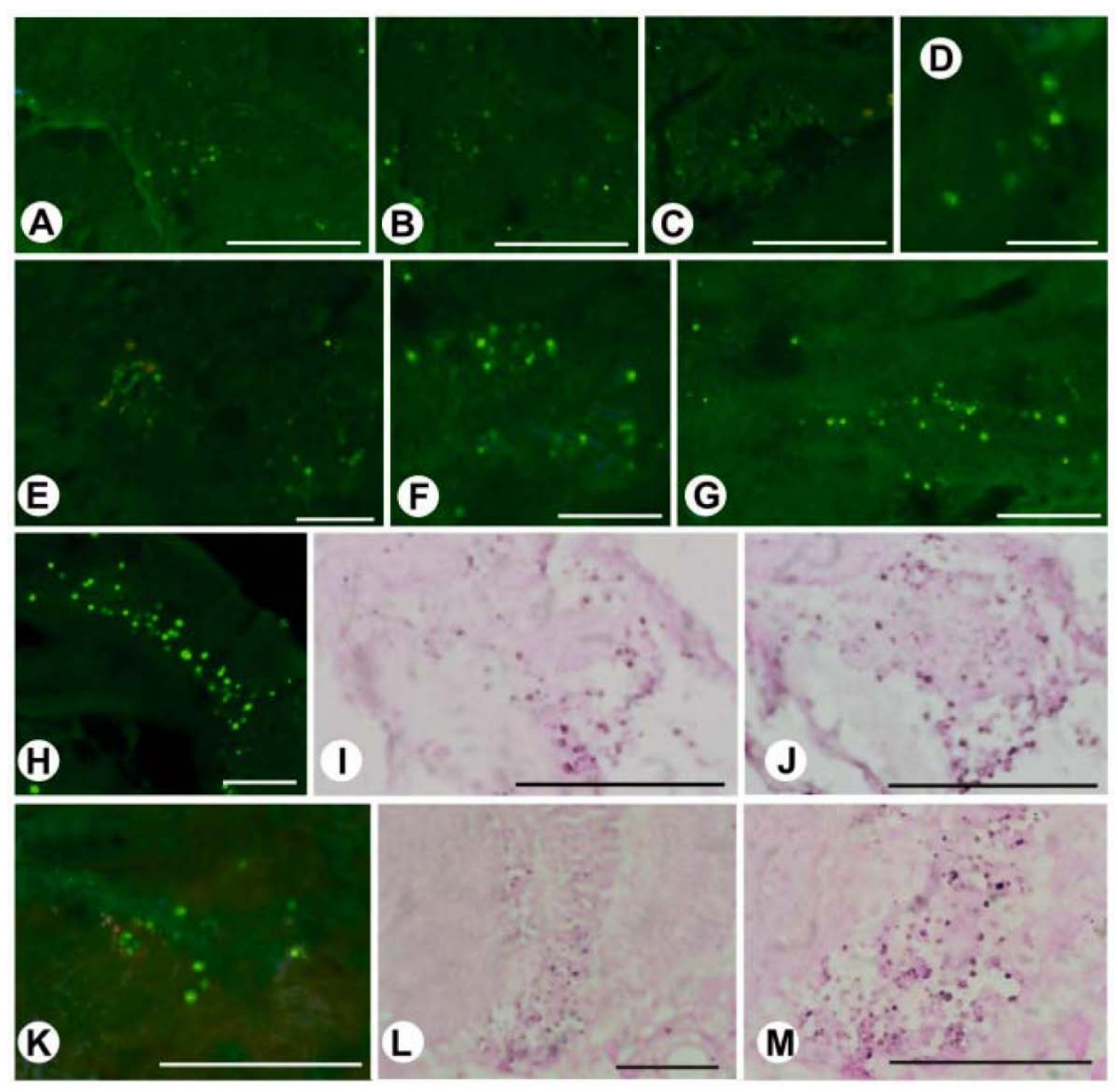

Figure 5. Micrographs of histological sections from the optic lobes of $A$. mellifera treated by the TUNEL reaction. (A-C). Fifth-instar larvae of queens, showing several marked nuclei, suggesting cell death during the initial differentiation process of the optic lobes. Bars: $100 \mu \mathrm{m}$. (D). Fifth-instar larvae of drones, showing a few marked nuclei at the edges of the optic lobe. Bars: $300 \mu \mathrm{m}$. (E and F). Marked nuclei in the optic lobes of prepupae queens. (G). Optic lobes showing marked nuclei in prepupae drones. Bars: $200 \mu \mathrm{m}$. (H-J). Optic lobes of white-eyed pupal queens. In (H), note the fluorescent marking and in (I) and (J) the marked nuclei after the signal conversion to light microcopy. Bars: $200 \mu \mathrm{m}$. (K-M). Pink-eyed pupae queens, showing, in (K), marked nuclei in the central region of the optic lobes and in (L) and (M), marked nuclei after the signal conversion to light microcopy. Bars: $100 \mu \mathrm{m}$. 


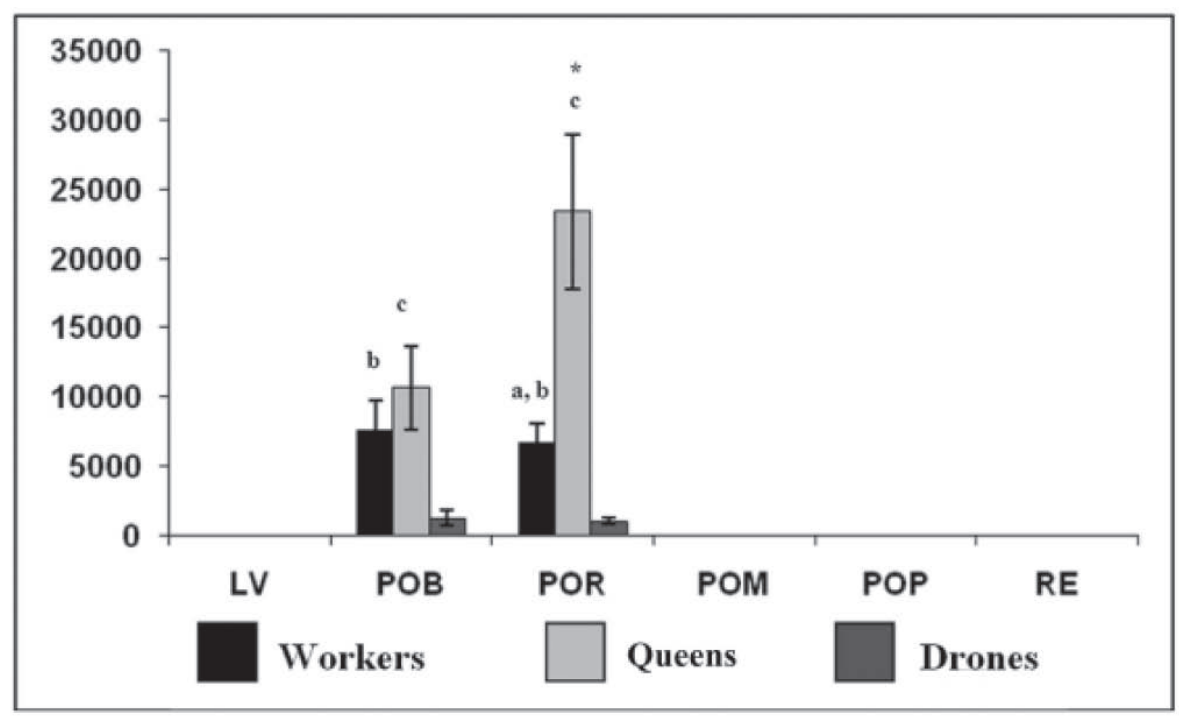

Figure 6. Mean values $\left(\mu \mathrm{m}^{2}\right)$ and standard deviations of areas of cell death measured in median-frontal sections of the optic lobes of workers, queens and males of Apis mellifera during metamorphosis. Different letters indicate significant differences $(P \leq 0.5$, Tukey multiple range test) between (a) workers and queens, (b) workers and males, and (c) queens and males.

In the BEP, BlEP and PPB stages of workers, queens and drones, the OL are completely differentiated and cell death is absent (figure 4).

\subsection{Cell death}

3.2.1 TUNEL reaction: In queens in the fifth-instar larval stage, the TUNEL reaction revealed the presence of cell death as early as in the OL primordia (figure $5 \mathrm{~A}-\mathrm{C}$ ). Reaction-positive nuclei were scattered throughout the OL, while drones in this stage (figure 5D) showed poorly marked nuclei, and the OL of workers in the fifth-instar larval stage showed a negative TUNEL reaction. In prepupal queens (figure 5E and F), several TUNEL-positive nuclei were visible in the OL, while in drones in the prepupal stage the nuclei were poorly marked (figure 5G). Queens in the WEP (figure 5H-J) and PEP (figure 5K-M) stages showed marked nuclei at the lateral edges of the OL. Workers had a negative TUNEL reaction in this stage. Positive TUNEL reactions were absent in the three classes of bees in the BEP stage.

3.2.2 Morphometry of cell death area: The areas of pyknotic nuclei, indicative of cell death, were measured in the WEP and PEP stages (figure 6). The results showed that cells with this morphology occupied significantly larger areas in queens, followed by workers. Therefore, cell death in drones is not as prevalent as in females.

\subsection{Mitosis}

Several cell nuclei showed immunomarked phosphorylated histone $\mathrm{H} 3$ in the OL of workers, queens and drones in the early stages of metamorphosis into larvae, prepupae and white-eyed pupae (figure 7).

In the OL of fifth-instar larvae (figure 7A-C) and prepupae (figure 7D-F) of workers, queens and drones, marked nuclei were present in large areas at the edges of the OL. All the individual classes in the WEP stage (figure $7 \mathrm{G}-\mathrm{I}$ ) showed mitosis at the outer border in the form of lamina neuroblasts. In drones in the PEP stage (figure 8A), the OL continued to show several marked nuclei indicative of mitosis, while in workers and queens (figure 8B), no cells undergoing mitosis were observed. Cell division, detected by immunoreaction to phosphorylated histone $\mathrm{H} 3$, was not observed in workers, queens or drones in the subsequent stages.

\section{Discussion}

The findings from this study indicate that OL differentiation follows a similar pattern in the three classes of individuals studied, without structural differences in their development. The main differences are in the rates and timing of cell division and cell death. Cell death was more frequent in queens and less frequent in drones, with workers showing an intermediate rate of cell death, while cell division proceeded for an extended time in drones compared with queens and workers.

High rates of cell division are expected during OL differentiation. However, as only the cells in mitosis which present condensed chromosomes are seen in histological preparations, these high rates are seldom observed. Therefore, methods that permit observation of the $\mathrm{S}$ phase, 
Figure 7. Fluorescence micrographs of the optic lobes of $A$. mellifera immunomarked with phosphorylated histone H3, showing several marked nuclei in fifth-instar larvae of workers (A), queens (B) and drones (C), in prepupae workers (D), queens (E) and drones (F), and in white-eyed pupae workers (G), queens (H) and drones (I). Bars: $400 \mu \mathrm{m}$.

such as incorporation of 5-bromo-2-deoxyuridine (BRdU) in DNA (Malun et al. 2003; Ganeshina et al. 2000), give a more exact measure. However, the blood-brain barrier makes it difficult to use this method, leading us to use the phosphorylated histone $\mathrm{H} 3$ immunoreaction to detect rates of cell division. This is a marker of chromosome condensation and, like the histological preparations, marks only the mitotic cells, resulting in the detection of a few mitosis events. Nevertheless, it was possible to observe that the period during which mitosis occurs in the OL lasts longer in males than in queens and workers.
The larvae of holometabolous insects display simplified behaviours, hatching early in a less developed condition. In the specific case of $A$. mellifera, the larvae are raised under the protection of brood cells inside the colony, where they are fed by the workers. The brain structures corresponding to adult organs, such as compound eyes and antennae, are practically absent in the larvae and develop only during pupation (Panov 1957; Farris et al. 1999).

Studies on the OL of Manduca sexta (Monsma and Booker 1969; Champlin and Truman 1998) and Drosophila melanogaster (Truman et al. 1993) indicate that the 

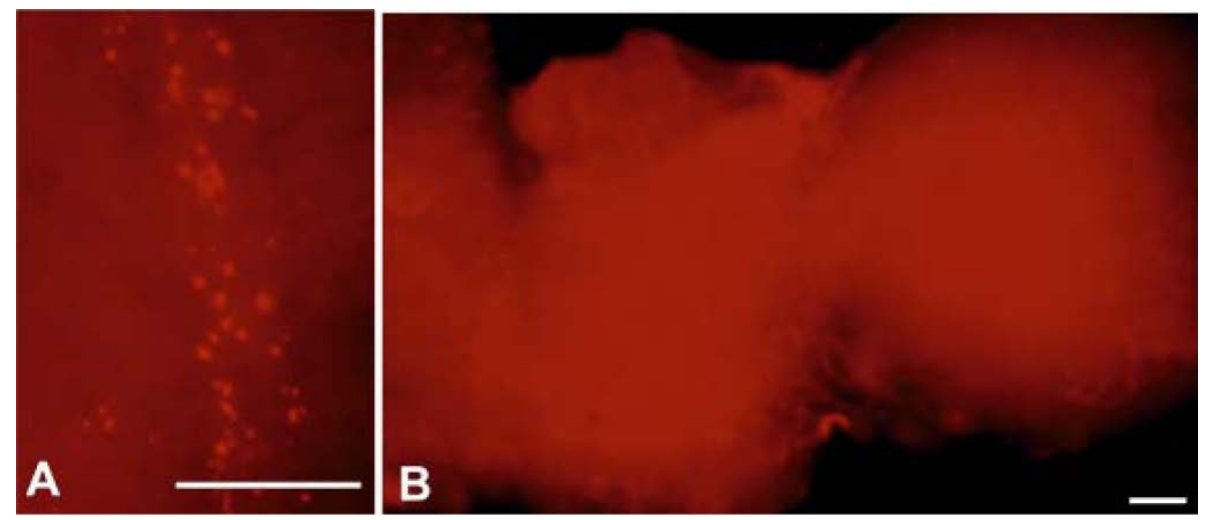

Figure 8. Fluorescence micrographs of the optic lobes of pink-eyed pupae of A. mellifera immunomarked with phosphorylated histone H3. (A) Optic lobes of drones with marked nuclei. (B) No nuclei are marked in queens at this stage. Bars: $400 \mu \mathrm{m}$.

developmental events in this organ occur in a manner similar to that observed in the mushroom bodies of $A$. mellifera (Panov 1957; Malun 1998). In both species, the brain neuroblasts divide symmetrically (Malun 1998) to produce large numbers of cells, which then divide asymmetrically to generate neurons. In addition, the authors suggest that neurogenesis decreases in both brain structures as development progresses, and that the neuroblasts then begin to die. The death of neuroblasts is ascribed to peaks of ecdysone in the haemolymph. The arrangement of the neuroblasts in columns perpendicular to the epidermis is evidence of symmetrical cell division.

The results of this study indicate that during OL differentiation, mitosis and cell death occur in all classes of individuals, albeit at different rates. The visual system of an adult insect consists of a retina containing photoreceptor cells, and the optic lobes, which comprise three ganglia: lamina, medulla and lobula. The retina cells form an ordered arrangement of repeated units of ommatidium (Ready et al. 1976). Each retinal unit (with eight to nine photosensory cells) within the ommatidium project axonal bundles towards the optical lobes forming synapses in the lamina, and possibly in the medulla. Neurons of the lamina in turn project axons into the medulla and the medulla then projects it to lobule (Horridge 1965). Based on this, lower cell death rates and higher cell division rates in the optic lobes of drones, as showed in the present study, would result in a larger number of neurons in this brain structure. This larger number of neurons will lead to a greater amount of nerve connections between the optic lobe and the compound eyes. This fact, added to the fact that the compound eyes of $A$. mellifera drones are much larger than those of females (drones have 7000-8000 ommatidia in each compound eye, while workers have 4000-5000, and queens have 3000-4000 (Snodgrass 1956), results in better visual acuity in drones.

\section{Acknowledgements}

The authors gratefully acknowledge the financial support of FAPESP (Fundação de Amparo à Pesquisa do Estado de São Paulo) through grant no. 04/03336-0. Thanks are given to Dr Klaus Hartfelder from the Departamento de Biologia Celular e Molecular e Bioagentes Patogênicos, Faculdade de Medicina de Ribeirão Preto, Universidade de São Paulo, Brazil.

\section{References}

Butler C G 1957 The process of queen supersedure in colonies of honeybees (Apis mellifera); Insectes Soc. 4 211-223

Champlin D T and Truman J W 1998 Ecdysteroid control of cell proliferation during optic lobe neurogenesis in the moth Manduca sexta; Development 125 269-277

Chapman R F 1998 The insects: structure and function (New York: Cambridge University Press)

Cruz-Landim C, Chaud-Netto J E and Gonçalves L S 1979 Morphological alterations in the compound eyesof eye-color mutants of Apis mellifera L. (Hymenoptera - Apidae); Rev. Bras. Genét. II 3 223-231

Doolittle G M 1899 Doolittle queen-rearing methods; Am. Bee J. 39 435-436

Fahrbach S E, Strande J L, Robinson G E 1995 Neurogenesis is absent in the brains of adult honeybees and does not explain behavioural plasticity; Neurosci. Lett. 197 145-148

Farris S M, Robinson G E, Davis R L and Fahrbach S E 1999 Larval and pupal development of the mushroom bodies in the honey bee, Apis mellifera; J. Comp. Neurol. 414 97-113

Ganeshina O, Schafer S and Malun D 2000 Proliferation and programmed cell death of neuronal precursors in the mushroom bodies of the honeybee; J. Comp. Neurol. 417 349-365

Gurley L R, D_Anna J A, Barhan S S, Deaven LL and Tobey R A 1978 Histone phosphorylation and chromatin structure during mitosis in Chinese hamster cells; Eur. J. Biochem. 84 $1-15$ 
Hendzel M J, Wie Y, Mancini M A, Van Hooser A, Ranalli T, Brinkley B R, Bazett-Jones D P and Allis C D 1997 Mitosis specific phosphorylation of histone $\mathrm{H} 3$ initiates primarily within pericentromeric heterochromatin during G2 and spreads in an ordered fashion coincident with mitotic chromosome condensation; Chromosoma 106 348-360

Horridge G A 1965 Arthropoda: receptors for light, and optic lobes; in Strcture and function of the nervous system of invertebrates (Eds) T H Bullock and G A Horridge (eds), (San Francisco: Freeman W H) vo;1 II, pp 1063-1113

Ito K and Hotta Y 1992 Proliferation pattern of postembryonic neuroblasts in the brain of Drosophila melanogaster; Dev. Biol. 149 134-148

Malun D 1998 Early development of mushroom bodies in the brain of the honeybee Apis mellifera as revealed by BrdU incorporation and ablation experiments; Learn. Memory 5 90-101

Malun D, MoseleitAD and Grünewald B 2003 20-hydroxyecdysone inhibits the mitotic activity of neuronal precursors in the developing mushroom bodies of the honeybee Apis mellifera; J. Neurobiol. 57 1-14

Monsma S A and Booker R 1969 Genesis of the adult retina and outer optic lobes of the moth Manduca sexta. I. Patterns of proliferation and cell death; J. Comp. Neurol. 367 10-20

Norlander R H and Edwards J S 1970 Postembryonic brain development in the monarch butterfly, Danaus plexippus plexippus. L. III. Morphogenesis of centers other than the optic lobes; Roux Arch. Dev. Biol. 164 247-260
Panov A A 1957 The structure of the brain in insects in successive stages of postembryonic development; Rev. Entomol. URSS 36 269-284

Paulson J R and Taylor S S 1982 Phosphorylation of histones 1 and 3 and nonhistone high mobility group 14 by an endogenous kinase in HeLa metaphase chromosomes; J. Biol. Chem. 257 6064-6072

Ready D F, HansonT E and Benzer S 1976 Development of the Drosophila retina, a neurocrystalline lattice; Dev. Biol. 53 217-240

Siegel S and Castellan N J Jr 1988 Nonparametric statistics for the behavioral sciences $2^{\text {nd }}$ edition (New York: Mc Graw-Hill)

Snodgrass R E 1935 Principles of insect morphology (New York, London: McGraw-Hill Book Company)

Snodgrass R E 1956 Anatomy of the honey bee (Ithaca, New York: Comstock Publishing Associates)

Truman J W and Bate M 1988 Spatial and temporal patterns of neurogenesis in the central nervous system of Drosophila melanogaster; Dev. Neurosci. 125 145-157

Truman J W, Taylor B J and Awad T A 1993 Formation of the adult nervous system; in The development of Drosophila melanogaster (Eds) M Bate and A Martinez-Arias (Cold Spring Harbor, NY: Cold Spring Harbor Laboratory Press) pp 1245-1275

Verheijen-Voogd C 1959 How workers bees perceive the presence of their queen; Z. Vergl. Physiol. 41 527-528

Winston M L 1987 The biology of the honeybee (Cambridge: Harvard University)

MS received 17 August 2009; accepted 16 July 2010

ePublication: 10 August 2010

Corresponding editor: ELLEN LARSEN 